\title{
ANÁLISE DA EXPERIÊNCIA DO TRABALHO REMOTO EM HOME OFFICE DE PROFESSORES DO ENSINO SUPERIOR
}

\author{
REMOTE WORKING FROM HOME EXPERIENCE ANALYSIS \\ OF HIGHER EDUCATION TEACHERS
}

\author{
Giovana Mara Zugliani Bortolan ${ }^{1}$, M.Sc, \\ gmzugliani@gmail.com e https://orcid.org/0000-0002-2000-9542 \\ Flávio Anthero Nunes Vianna dos Santos ${ }^{2}$, D.Eng, \\ flavio.santos@udesc.br e http://orcid.org/0000-0002-9670-0954 \\ Susana Cristina Domenech ${ }^{3}$, D.Eng, \\ scdomenech@gmail.com e https://orcid.org/0000-0001-7517-0723 \\ Marcelo Gitirana Gomes Ferreira ${ }^{4}$, D.Eng, \\ marcelo.gitirana@gmail.com e https://orcid.org/0000-0003-1912-9982
}

134 Laboratório de Interfaces e Interações em Tecnologias Assistivas (Li2TA), Universidade do Estado de Santa Catarina (UDESC), Florianópolis, Brasil.

trabalho remoto, home office, professor do ensino superior, coronavírus A pesquisa tem como objetivo compreender a experiência do trabalho remoto em home office de professores do ensino superior de instituições públicas durante a pandemia do coronavírus. Dessa forma, foi realizado um levantamento bibliográfico sobre o tema e pesquisa de inquirição por meio de um questionário eletrônico. O questionário obteve 84 respostas de professores do ensino superior que passaram a trabalhar em casa durante a pandemia. Os profissionais compartilharam a experiência no trabalho em home office, relatando os desconfortos, vantagens, desvantagens, problemas na estação de trabalho, produtividade, aspectos emocionais e o grau de satisfação com o ambiente.

remote work, work from home, high education teacher, coronavirus

The research aims to understand the remote work from home experience of high education teachers of public institutions during a coronavirus pandemic. Thus, a bibliographical survey on the subject and inquiry research were carried out through an electronic questionnaire. The questionnaire obtained 84 answers from higher education teachers who started working at home during the pandemic. The professionals shared their experience of working from home, reporting the discomforts, advantages, disadvantages, problems at the workstation, productivity, emotional aspects, and the degree of satisfaction with the environment. 


\section{Introdução}

Por muito tempo as residências foram vistas como refúgio da rotina de trabalho e aceleração do ritmo de vida. Entretanto, com as tecnologias, foi possível transferir o ambiente de escritório para a casa, de modo a conciliar fatores pessoais com o trabalho. Apesar das vantagens para os usuários que optaram pelo trabalho remoto, com a pandemia da COVID-19, ocasionada pelo novo coronavírus da síndrome respiratória aguda grave 2 (SARS-CoV-2), o teletrabalho necessitou ser realizado exclusivamente em home office e os trabalhadores de escritórios físicos foram forçados a adaptar suas casas. Grande parte destes trabalhadores não tinham estrutura física para tal; conhecimento e treinamento em ergonomia; e somado às mudanças, inseguranças e dificuldades apresentadas, surgiram problemas de saúde física e psicológica.

De acordo com Godoy (2019), a satisfação dos teletrabalhadores carece de estudos empíricos que os atendam de forma efetiva. Bortolan, Domenech e Ferreira (2021) observaram, por meio de uma Revisão Bibliográfica Sistemática (RBS), que grande parte das pesquisas analisadas - anteriores a pandemia - objetivavam compreender a atividade de teletrabalho e poucos estudos avaliaram o espaço físico e a estação de trabalho. Os principais aspectos analisados até então, eram relativos à quantidade de horas trabalhadas (KIM et al., 2020; KOSSEK; LAUTSCH; EATON, 2006); o isolamento social e índice de distrações (BENTLEY et al., 2016; FONEER; ROLOFF, 2010; WANG; ALBERT; SUN, 2020); às interferências do ambiente familiar no trabalho; à falta de comunicação com a organização e com a equipe de trabalho (BENTLEY et al., 2016); à carga mental e ao excesso de exposição às tecnologias ${ }^{1}$ (SUH; LEE, 2017; MOLINO et al., 2020).

No entanto, a necessidade dos usuários em se adaptarem à situação enfatiza a importância de analisar outras variáveis que envolvem a experiência de teletrabalho em home office, de forma a efetuar uma análise mais abrangente. Como o home office tornou-se uma opção para muitos trabalhadores, os usuários necessitarão de suporte adequado em relação à ergonomia, caso contrário, o desconforto irá progredir e gerar condições prejudiciais, tais como os distúrbios musculoesqueléticos (DAVIS et al., 2020). Como observado por GarcíaSalirrosas e Sáchez-Poma (2020), há uma alta prevalência de transtornos musculoesqueléticos associado a fatores de risco ergonômico, como postura prolongada, longas horas de trabalho, móveis inadequados e movimentos repetitivos de punho. Estes fatores, consequentemente, geram dor nos membros superiores e lesões na região lombar (GARCÍA-SALIRROSAS; SÁCHEZ-POMA, 2020), levando o usuário ao estresse, riscos psicossociais e exaustão emocional (WANG; ALBERT; SUN, 2020; BJÄRNTOFT, et al., 2020).

Apesar dos riscos referentes a ergonomia física, no decorrer dos meses com a flexibilização das medidas restritivas contra a propagação da Covid-19, a percepção do usuário em relação ao home office mudou. O equilíbrio do trabalho com a vida pessoal e a melhoria no desempenho e produtividade foram apontados como fatores decisivos para a continuidade do home office (IPSEN et al., 2021). De acordo com o estudo feito pela Pulses, $78 \%$ dos brasileiros se sentem mais produtivos trabalhando remotamente (LIMA, 2020). No entanto, mesmo com esse aumento na produtividade, ainda há a preocupação de transformar um único ambiente apto para as duas atividades contrastantes: a casa e o trabalho. De acordo com Ipsen et al. (2021) a falta de ergonomia no espaço de trabalho e as ferramentas inadequadas são as principais desvantagens da modalidade.

Neste contexto, uma das profissões mais impactadas pela pandemia é a dos docentes de ensino superior. A suspensão repentina das aulas presenciais "aumentou a demanda de trabalho dos professores, exigindo adaptação no método de ensino e readequação da vida doméstica" (MOROSINI, 2020, p.27). Para alguns, a experiência no trabalho remoto tem sido pior e gerou desgaste devido aos desafios e a falta de um espaço próprio para o trabalho em casa. Mancebo (2020, p. 110) enfatiza que o ensino remoto "merece um destaque nesta discussão, pelos impactos que podem trazer para esses trabalhadores, para as instituições de ensino superior e para a própria educação pública".

${ }^{1}$ Em inglês, tecnoestresse. 
Como afirma Godoi et al. (2020) é importante ressaltar que educação à distância (EaD) e o ensino remoto emergencial (ERE) não são similares. $\mathrm{O}$ ensino à distância é uma modalidade na qual a aprendizagem ocorre com a utilização de tecnologias de informação e comunicação para estudantes e profissionais que estejam em lugares e tempos diferentes (BRASIL, 2017). Mancebo (2020) explica que o EaD exige um planejamento cuidadoso e específico, diferente da didática utilizada em aulas presenciais, pois conta com o apoio de materiais apropriados e elaborados com uma linguagem e com um conteúdo que atendam a essa estratégia. Além disso, os profissionais que atuam no sistema de $\mathrm{EaD}$ são qualificados para essa modalidade de ensino.

Dessa forma, esta pesquisa visa compreender a experiência do trabalho remoto em home office de professores do ensino superior, de instituições públicas, durante a pandemia do coronavírus, por meio da revisão de literatura e pesquisa de inquirição.

\section{Método}

A pesquisa se caracteriza, de acordo com os objetivos estabelecidos, como um estudo de natureza qualitativa descritiva, pelo estudo e inquirição das características dos participantes; como meio de descobrir a existência de associações entre variáveis e como forma de proporcionar uma nova visão do problema (GIL, 2010).

O processo foi dividido em duas etapas: (1) levantamento bibliográfico sobre o tema e (2) pesquisa de inquirição por meio da aplicação de questionário eletrônico. No primeiro momento, foi realizado um levantamento bibliográfico sobre teletrabalho, home office e fatores humanos para a familiarização com o problema com vistas a torná-lo compreensível. Em seguida, o trabalho assume característica descritiva, pois visa prover conhecimento sobre o assunto. Segundo Mattar (2014), este tipo de pesquisa pode ser aplicado como um passo inicial para o processo contínuo do estudo. Além disso, de acordo com o autor, promove a familiaridade, conhecimento e compreensão sobre o problema. Moraes e Mont'Alvão (2010) explicam que no contexto científico, a pesquisa de inquirição tem como objetivo buscar informações metódicas para, posteriormente, quantificá-las.

Para a aplicação da pesquisa, foi elaborado um questionário na plataforma Google Forms, com base no levantamento bibliográfico, e constituiu de quatro partes: (1) termo de consentimento livre e esclarecido (TCLE); (2) dados sociodemográficos; (3) experiência no trabalho remoto; e (4) usuário e satisfação no trabalho em home office. Foi realizado uma análise semântica para verificar se todos os itens são compreensíveis e contemplam os objetivos da pesquisa. Para a análise semântica, Pasquali (1998) sugere uma técnica de análise que consiste em checar com um número de três a cinco pessoas dos mais diversos estratos. Foram selecionados: um (01) especialista em língua portuguesa, um (01) especialista em teletrabalho, dois (02) especialistas em ergonomia e um (01) membro leigo para analisar os itens e indicar sugestões quanto à elaboração, avaliação e compreensão do questionário completo.

A primeira página do questionário consistiu na apresentação do TCLE, que informava sobre o objetivo da pesquisa, os riscos do procedimento, a preservação da identidade e a liberdade para interromper o preenchimento do formulário a qualquer momento. Além disso, foi comunicado que a utilização dos dados sem identificação é somente para a produção de artigos técnicos e científicos. Assim, a primeira questão era uma pergunta sobre a concordância ou discordância da participação. Somente seria possível dar início ao questionário se o indivíduo assinalasse a alternativa de concordância com os termos e condições de sua participação na pesquisa. Os participantes indicavam seu consentimento e iniciavam o preenchimento do questionário.

As perguntas referentes aos dados sociodemográficos, experiência no trabalho remoto e satisfação no trabalho em home office foram elaboradas de forma aberta e fechada (análise univariada), sendo que em alguns casos o participante tinha a possibilidade de responder a mais de uma alternativa (análise 
multivariada). As perguntas abertas foram analisadas individualmente e exportadas com auxílio dos softwares Microsoft Word e Excel 365. Os dados foram analisados, comparados e categorizados dentro das abordagens e objetivos da pesquisa. As perguntas fechadas foram analisadas por meio do software IBM SPSS Statistics 23. Para a análise univariada, foi considerada uma variável categorizada em forma de dados nominais ou ordinais. Para a análise multivariada, foi pontuado zero quando o usuário não assinalou a alternativa e um (01) quando assinalou. Os dados foram analisados descritivamente por meio da distribuição de frequências e referência cruzada.

Para a representação gráfica das emoções, foi utilizado como base, o 'Circumplex of Affect' desenvolvido por Russell (1980). Neste modelo, as emoções foram distribuídas em um plano bidimensional, sendo o eixo $\mathrm{X}$ representado pela valência (valence) e o eixo Y representado pela excitação (arousal). Nesta estrutura, a valência se refere ao grau positivo e negativo da emoção e é uma dimensão da experiência que está relacionada ao tom hedônico (BARRETT; RUSSELL, 1999). Já a excitação se refere à intensidade da emoção. Por meio do modelo de Russell (1980), os estados emocionais podem ser apresentados em qualquer nível de valência e excitação. Para a seleção das emoções, foram coletadas dez emoções positivas e dez negativas, identificadas por Russell (1980) e Plutchik (1991).

A análise destes dados ocorreu da seguinte maneira: cada associação emocional dos participantes foi substituída por um valor numérico de 1 ou -1, dependendo dos valores de excitação ou de valência afetiva encontrados (BARRETT; RUSSELL, 1999; RUSSELL, 1980). Assim, as respostas referentes a emoção "Felicidade" foram substituídas pelo par 1 e 1, porque a "Felicidade" pode ser entendida como sendo uma emoção com alto índice de excitação (1) e valência afetiva positiva (1); respostas emocionais negativas como o "Medo" foram substituídas pelo par 1 e -1, porque esta categoria emocional sugere alto índice de excitação (1) e valência afetiva negativa (-1). Este tipo de análise possibilitou o cálculo de um valor numérico médio de excitação e de valência afetiva para cada emoção selecionada neste estudo (RAMOS; BUENO, 2012; BARRETT; RUSSELL, 1999; RUSSELL, 1980).

Para a aplicação do questionário, foram convidados a participar professores do ensino superior de instituições públicas, que passaram a trabalhar em home office durante a pandemia do coronavírus. Não foram considerados professores que atuam na modalidade $\mathrm{EaD}$. O contato com os participantes foi realizado por meio de endereço eletrônico pessoal e institucional, e redes sociais com abrangência nacional. A aplicação do questionário foi realizada totalmente de forma online.

Devido às limitações de tempo, recursos financeiros e materiais, a amostra é caracterizada como não probabilística por conveniência. Os resultados só se aplicam à amostra construída, não sendo possível generalizar os dados para a população. Contudo, os resultados são úteis para a construção do conhecimento e para o início de investigações sobre a temática (MATTAR, 2014).

\section{Resultados e Discussão}

\subsection{Amostra e dados sociodemográficos}

A pesquisa contou com a participação de 84 docentes do ensino superior de instituições públicas que passaram a trabalhar em ambiente de home office durante a pandemia do coronavírus. Os participantes foram convidados a responder um questionário online, entre os meses de setembro de 2020 e maio de 2021.

Dentre os participantes, $38,1 \%$ eram do sexo feminino e $61,9 \%$ do sexo masculino. A média da idade foi de 41 anos. A idade mínima foi de 26 anos e a máxima 72 anos. Com relação a moda, a idade que mais se repetiu foi de 35 anos. Os docentes participantes da pesquisa estão localizados nas cinco regiões brasileiras, sendo $2,4 \%$ da região norte; $3,6 \%$ da região centro-oeste; $17,9 \%$ da região nordeste; $23,8 \%$ da região sudeste 
e 52,4\% da região sul. A Tabela 1 apresenta uma síntese dos dados sociodemográficos e laborais dos participantes.

\begin{tabular}{l|l|c}
\hline \multicolumn{2}{c|}{ Características sociodemográficas e laborais } & Frequência (\%) \\
\hline \multirow{2}{*}{ Sexo } & Feminino & 38,1 \\
\cline { 2 - 3 } & Masculino & 61,9 \\
\hline \multirow{2}{*}{ Trabalho remoto antes da pandemia } & Sim & 33,3 \\
\cline { 2 - 3 } & Não & 66,7 \\
\cline { 2 - 3 } & Problemas de saúde física & 10,9 \\
\hline \multirow{2}{*}{ Organização do trabalho remoto } & Flexível & 35,7 \\
\cline { 2 - 3 } & Com horários determinados & 22,6 \\
\cline { 2 - 3 } & Parcialmente com horários determinados \\
\hline \multirow{2}{*}{ Preferência pela modalidade de trabalho } & Híbrido & \\
\cline { 2 - 3 } & Presencial & \\
\cline { 2 - 3 } & Remoto & 51,7 \\
\hline
\end{tabular}

Tabela 1. Características sociodemográficas e laborais dos participantes

Fonte: Elaborado pelos autores (2021).

O trabalho dos docentes engloba o ensino (preparação, ministração das aulas e atendimento de alunos); a pesquisa (desenvolvimento de pesquisas acadêmicas); a extensão (atividades voltadas para comunidade externa); atividades administrativas (participação em colegiados, comissões, coordenação e chefias), além de orientações de alunos de graduação e pós-graduação, e divulgação de pesquisa por meio da participação em eventos.

Os participantes da pesquisa são docentes de cursos diversos, sendo 47,62\% de Matemática; $13,10 \%$ de Design; 4,76\% de Física e Administração; 3,57\% de Ciências Contábeis, Psicologia e Engenharia; 2,38\% de Artes Visuais, Letras, Educação Física e Pedagogia; 1,19\% de Moda, História, Sistemas de Informação, Comunicação Social, Ciências Políticas, Arquitetura, Ciências da Computação e Direito.

Os professores descreveram os itens que eles necessitam para executar as atividades de forma remota, como: computador (com uma ou duas telas, em alguns casos); internet banda larga; mesa digitalizadora (para representações gráfica e demonstrações matemáticas); tablets e celulares como mídias de apoio; microfone, fone de ouvido e câmera (para gravações de audio e imagem); softwares específicos da área de atuação e de edição de vídeo; aplicativos de videoconferência; e livros e artigos científicos físicos e digitais (por meio de acesso VPN). Além de acessórios de escritório como mobiliário (cadeira confortável e mesa grande), papelaria e impressora, alguns respondentes destacaram a necessidade da utilização de um quadro branco (por não conseguirem se adequar somente ao modo digital e por preferirem ministrar as aulas como se fosse no presencial). No entanto, há profissionais que se adequaram ao modo remoto e necessitam que o ambiente de fundo (onde realizam as gravações e reuniões) seja esteticamente agradável e organizado. Os professores também destacaram a importância de uma iluminação natural e artificial adequada, conforto térmico, organização e limpeza, e que o espaço de trabalho seja reservado dos demais ambientes da casa, de preferência, sem precisar dividir este cômodo com nenhum outro membro.

\subsection{Experiência no trabalho remoto}

Com relação a experiência no trabalho remoto, $66,7 \%$ dos respondentes afirmaram que não trabalhavam de forma remota antes da pandemia e 33,3\% responderam que sim. As atividades remotas, antes da pandemia, consistiam somente no desenvolvimento de pesquisas acadêmicas, preparação de aulas, correções de trabalhos e avaliações, e atividades administrativas que pudessem ser resolvidas por meio de endereço eletrônico. Dos 33,3\% dos respondentes que trabalhavam remotamente, 76,7\% disseram que as atividades remotas eram realizadas em home office; $20 \%$ não tinham um lugar específico e 1,2\% trabalhavam em espaço compartilhado (coworking). 
Os 84 profissionais também foram questionados se o trabalho é mais bem realizado de forma remota, presencial ou parcialmente remoto/presencial (híbrido). Para 58,3\% dos professores, o trabalho é melhor quando realizado de forma híbrida; $39,3 \%$ preferem trabalhar somente de forma presencial e 2,4\% gostaram de trabalhar exclusivamente de forma remota e preferem continuar trabalhando assim. Com relação a organização do trabalho, $41,7 \%$ dos professores realizam o trabalho parcialmente com horários determinados; $35,7 \%$ trabalham de forma flexível; e 22,6\% trabalham somente com horários determinados. Para alguns docentes, não ter horário fixo de trabalho acarreta o aumento da carga de trabalho. Já outros profissionais acreditam que a oportunidade de flexibilizar os horários torna o trabalho mais produtivo, além de auxiliar na organização de outras atividades.

Para os profissionais que já executavam parte do trabalho de forma remota, o ambiente de trabalho não foi totalmente comprometido. Entretanto, a situação da pandemia intensificou o trabalho realizado em casa. As interferências familiares, tecnológicas e o isolamento social tornou a experiência do home office menos agradável. Segundo relatos dos profissionais, a rotina de trabalho em casa não sofreu impactos pelo ambiente, mas pela forma de lecionar que precisou ser reformulada. Além da preparação das aulas, muitos docentes realizam gravações de vídeo (aulas assíncronas) que tornam o trabalho mais cansativo. Assim, os profissionais que preferem o trabalho de forma híbrida enfatizam que as aulas devem ser realizadas no modo presencial, mas parte do trabalho pode ser mais eficiente se realizada também em home office, como reuniões, pesquisas, orientações, entre outras atividades não relacionadas ao ensino. Os professores relataram que embora tenham se adaptado às ferramentas digitais, a avaliação do aprendizado dos alunos não tem sido satisfatória, por isso preferem o modo presencial. O ensino remoto não atende todas as competências do ensino presencial e a falta de interação com os alunos prejudica o resultado final do trabalho.

Com a implantação do ensino remoto emergencial, os profissionais precisaram dar continuidade às suas atividades em suas próprias residências. Assim, foi questionado em qual ambiente da casa eles estão trabalhando no momento (Tabela 2). Para esta questão, os participantes podiam assinalar mais de uma resposta. Sendo assim, 58,3\% dos docentes possuem um lugar da casa específico para trabalhar (home office); $32,1 \%$ estão trabalhando no quarto; $16,7 \%$ na sala de jantar; $14,3 \%$ na sala de $t v ; 7,1 \%$ afirmaram trabalhar em qualquer lugar da casa e 1,2\% informou trabalhar na cozinha.

\begin{tabular}{l|c}
\hline \multicolumn{1}{c|}{ Lugar da casa } & Frequência (\%) \\
\hline Home Office & 58,3 \\
\hline Quarto & 32,1 \\
\hline Sala de Jantar & 16,7 \\
\hline Sala de Tv & 14,3 \\
\hline Qualquer lugar da casa & 7,1 \\
\hline Cozinha & 1,2 \\
\hline
\end{tabular}

Tabela 2. Frequência do cômodo da casa que mais utiliza para trabalhar Fonte: Elaborado pelos autores (2021).

Apesar de 58,3\% dos docentes possuírem um home office, 7,8\% destes afirmaram trabalhar também em outros cômodos como sala de tv, sala de jantar e quarto. Os docentes que não possuem um espaço exclusivo de trabalho relataram que sentem falta de trabalhar em um local que não seja o mesmo em que descansam. $O$ isolamento social e a pandemia, neste caso, intensificaram a insatisfação com o trabalho, pois os profissionais passam o dia todo no mesmo cômodo. Para estes docentes, trabalhar e descansar no mesmo ambiente interfere na qualidade do sono, aumenta o cansaço e diminui o desempenho no trabalho. A Figura 1 apresenta cinco exemplos de profissionais que não possuem um home office e de como eles adaptaram outros cômodos da casa para o trabalho: quarto, sala de tv e sala de jantar. 

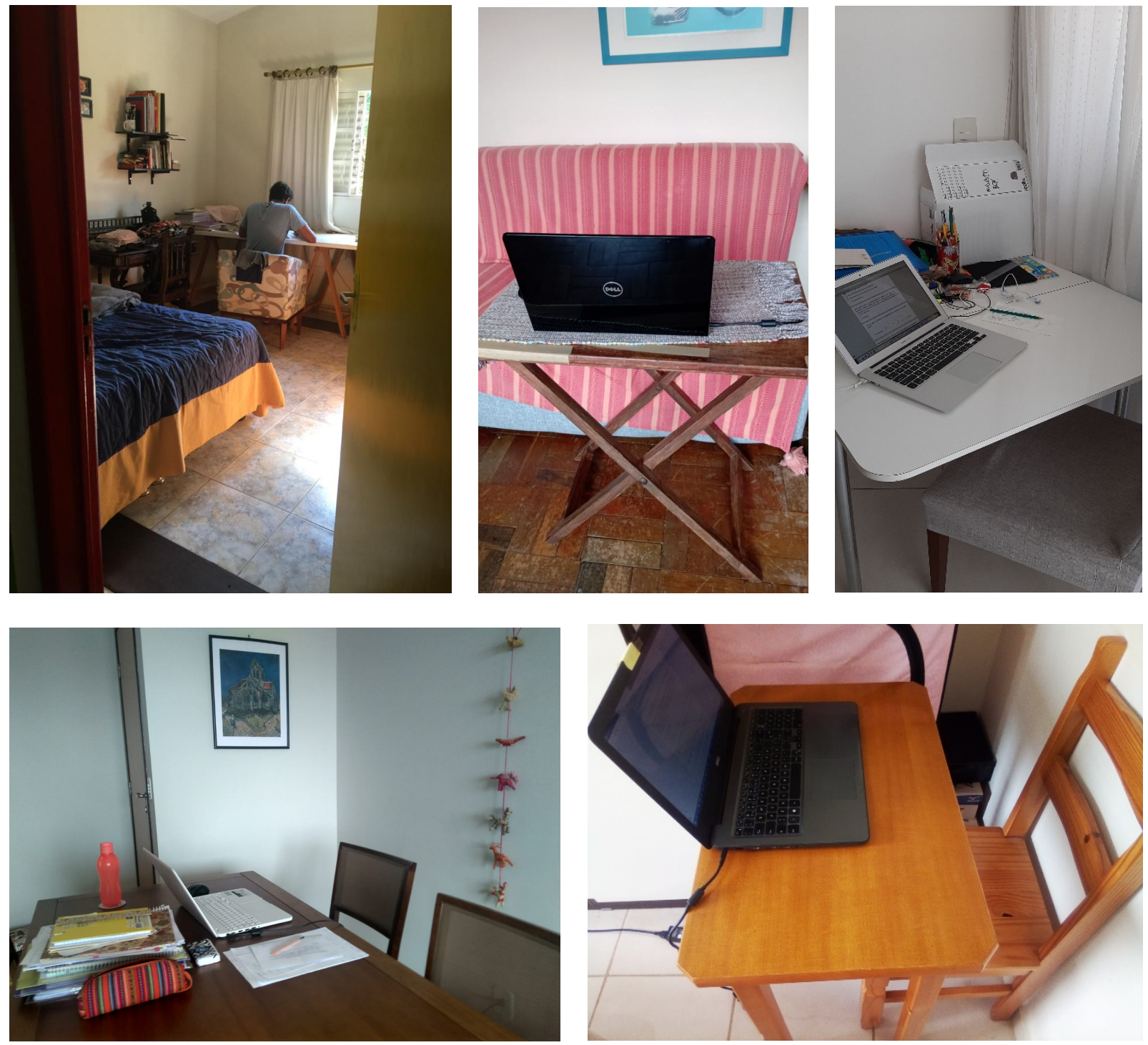

Figura 1. Espaços alternativos de trabalho em casa Fonte: Os autores (2021).

Para compreender melhor a experiência no trabalho remoto, foram elencadas as vantagens da modalidade: equilíbrio da vida doméstica e profissional (GIMÉNEZ-NADAL; MOLINA; VELILLA, 2020; FONNER; ROLOFF, 2010); redução do deslocamento entre a casa e o trabalho (TREMBLAY, 2002) flexibilidade de horário (DIMA et al., 2019; MANN; HOLDSWORTH, 2003; MACÊDO et al., 2020; DWIDIENAWATI et al, 2020; FILARDI; CASTRO; ZANINI, 2018); autonomia (FONNER; ROLOFF, 2010); índices baixos de interrupção e distração (BENTLEY et al., 2016; KAZEKAMI, 2020). Também foi acrescentada a opção de não haver vantagens e outras vantagens. Neste caso, os participantes tinham a opção de assinalar mais de uma vantagem (Tabela 3). Sendo assim, a maioria dos respondentes consideram a redução do deslocamento entre a casa e o trabalho $(77,4 \%)$ e a flexibilidade de horários $(65,5 \%)$ como sendo as maiores vantagens da modalidade. Em seguida, aparecem o equilíbrio com a vida doméstica (31\%); a autonomia $(29,8 \%)$ e o baixo índice de interrupção e distração $(13,1 \%)$.

As vantagens elencadas possuem resultados diferentes da literatura. Devido a pandemia, grande parte dos respondentes não consideram como vantagem o equilíbrio da vida doméstica, pois outros membros da 
família como cônjuges, filhos e parentes também estão desenvolvendo suas atividades em casa, assim há aumento no índice de interrupção e distração.

\begin{tabular}{l|c|c}
\hline \multicolumn{1}{c|}{ Vantagens do trabalho remoto } & \multicolumn{2}{c}{ Respostas } \\
\cline { 2 - 3 } & Número de respostas & Frequência (\%) \\
\hline Redução do deslocamento casa-trabalho/trabalho-casa & 65 \\
\hline Flexibilidade de horários & 57,4 \\
\hline Equilíbrio do trabalho com a vida doméstica & 65,5 \\
\hline Autonomia & 31 & 26 \\
\hline Baixo índice de interrupção e distração & 25 \\
\hline Não há vantagens & 11 \\
\hline Outras vantagens & 13,1 \\
\hline Total & 10,7 & 3 \\
\hline
\end{tabular}

Tabela 3. Frequência das vantagens do trabalho remoto Fonte: Elaborado pelos autores (2021).

Para $10,7 \%$ dos participantes não há vantagens no trabalho remoto e 3,6\% dos participantes apresentaram outras vantagens, como o fato de não precisar levar seus pertences diariamente para a universidade, como alimentos, livros, entre outros elementos fundamentais para a realização do trabalho. Para o respondente, é uma vantagem não precisar dividir os seus pertences em dois lugares (casa e universidade). Outra vantagem é a utilização de roupas confortáveis, economia com combustível e restaurantes; a tranquilidade de estar no conforto da casa e a oportunidade de uma vida mais saudável em termos de alimentação e prática de exercícios físicos. A maioria dos professores tinham o hábito (devido à distância entre a casa e o trabalho) de realizarem as refeições na universidade que trabalham ou nos arredores da mesma. Trabalhar em casa traz a vantagem de preparar as próprias refeições de maneira mais saudável e econômica. Além disso, os profissionais perceberam um melhor aproveitamento no tempo que antes era gasto no trânsito com outras atividades, como prática de atividade física e cursos extras.

Entre as desvantagens apresentadas na literatura, destacam-se: a quantidade de horas trabalhadas (KIM et al., 2020); o isolamento social (BENTLEY et al., 2016; FONEER; ROLOFF, 2010; WANG; ALBERT; SUN, 2020); a desatualização profissional; interferências do ambiente familiar no trabalho; interferências tecnológicas; ausência ou falta de adequação ergonômica na área de trabalho (MANN; HOLDSWORTH, 2003; GODOY, 2019); falta de comunicação com a organização e com a equipe de trabalho (BENTLEY et al., 2016) e diminuição na progressão de carreira e oportunidades (VAN STEENBERGEN et al., 2018; MANN; HOLDSWORTH, 2003).

\begin{tabular}{|c|c|c|}
\hline \multirow{2}{*}{ Desvantagens do trabalho remoto } & \multicolumn{2}{|c|}{ Respostas } \\
\hline & Número de respostas & Frequência (\%) \\
\hline Isolamento social & 51 & 60,7 \\
\hline Quantidade de horas trabalhadas (maiores do que em escritório físico). & 50 & 59,5 \\
\hline Interferências familiares & 40 & 47,6 \\
\hline Ausência de um espaço exclusivo de trabalho & 29 & 34,5 \\
\hline Dificuldade de comunicação com superiores e/ou colegas & 25 & 29,8 \\
\hline Falta de conforto no espaço de trabalho & 24 & 28,6 \\
\hline Interferências tecnológicas (computador, internet etc.) & 19 & 22,6 \\
\hline Desatualização Profissional & 6 & 7,1 \\
\hline Outras desvantagens & 4 & 4,8 \\
\hline Não há desvantagem & 0 & 0 \\
\hline Total & 248 & 295 \\
\hline
\end{tabular}

Tabela 4. Frequência das desvantagens do trabalho remoto Fonte: Elaborado pelos autores (2021).

A Tabela 4 apresenta que, o isolamento social (60,7\%); a quantidade de horas trabalhadas $(59,5 \%)$ e as interferências familiares $(47,6 \%)$ são as principais desvantagens para estes profissionais. Em seguida, a ausência de um espaço exclusivo de trabalho (34,5\%); a dificuldade de comunicação com superiores e 
colegas $(29,8 \%)$; falta de conforto no espaço de trabalho $(28,6 \%)$ e interferências tecnológicas $(22,6 \%)$ são em partes, as desvantagens consequentes das medidas emergências impostas pela pandemia. Com isso, observa-se que a recorrência das desvantagens é muito maior que as vantagens. Entretanto, por se tratar de uma profissão em que, constantemente os profissionais estão se atualizando e trabalhando com pesquisas acadêmicas, a desatualização profissional foi apontada somente por 7,1\% dos participantes. Essa desatualização, é o que a literatura chama de "aprendizagem informal", a aprendizagem do dia a dia na interação com colegas (CHARALAMPOUS et al., 2019).

Nenhum participante indicou que não há desvantagens, no entanto $4,8 \%$ dos docentes apresentaram outras desvantagens, como: a falta de interação com alunos e colegas nos corredores da universidade. Para este participante, a comunicação constrói e solidifica o conhecimento de várias maneiras. Outro participante relatou que só há vantagens em trabalhar em casa quando o trabalho remoto é uma opção do trabalhador, o que não é o caso dos professores. Ministrar aulas devido a uma medida emergencial diminuiu a qualidade das aulas e, mesmo com a organização do trabalho e a delimitação dos horários, ainda assim é demandada outras atribuições que tornam o trabalho exaustivo. Outras desvantagens são a não diferenciação entre o espaço doméstico e o de trabalho e a manutenção de uma rotina. Segundo o docente, é bem mais complexo manter uma rotina quando não há outros horários para respeitar, como a chegada ao trabalho e horário de almoço. Dessa forma, os profissionais não conseguem se desvincular do trabalho e estendem as horas recomendadas.

\subsection{Usuário e satisfação no trabalho em home office}

Sobre o trabalho remoto em home office, $75 \%$ dos docentes sentem algum tipo de desconforto físico ou mental, e $25 \%$ afirmaram não sentirem desconforto. Os professores informaram os principais desconfortos experenciados, sendo possível assinalar mais de um: cansaço mental $(82,8 \%)$; dores no corpo $(68,8 \%)$; desconforto visual $(48,4 \%)$; dor de cabeça $(26,6 \%)$ e outros desconfortos $(20,3 \%)$. Os profissionais descreveram - por escrito - os outros desconfortos, e os mais recorrentes foram: a não separação do ambiente de trabalho com o espaço de lazer e o ruído. Além destes desconfortos, também foram citados: (i) insônia, devido ao excesso de trabalho e tempo de exposição à tela; (ii) atividade muscular involuntária (bruxismo), devido ao estresse; (iii) estresse, de pela falta de comunicação com alunos e servidores; (iv) irritabilidade; (v) cansaço físico, por ficar muito tempo na mesma posição (causando inchaço nos membros inferiores) e (vi) ansiedade.

Foi questionado aos docentes se eles saberiam apontar quais as principais causas destes desconfortos (sendo possível assinalar mais de uma opção). As principais causas foram: excesso de trabalho $(67,7 \%)$; isolamento social (44,6\%); inadequação do espaço físico (41,5\%); interferências familiares e tecnológicas $(36,9 \%)$; sedentarismo (36,9\%); excesso de reuniões e interrupções provenientes do trabalho $(32,3 \%)$; distração $(21,5 \%)$; o fato de já possuir um problema físico que se intensificou com o trabalho remoto $(10,8 \%)$ e não souberam identificar $(4,6 \%)$. A Tabela 5 apresenta uma referência cruzada entre o desconforto e as causas do desconforto. Para $76,2 \%$ dos docentes, o cansaço mental é devido ao excesso de trabalho (59,4\%); ao isolamento social $(39,1 \%)$ e a inadequação do espaço físico (35,9\%). Em seguida, as dores no corpo (66,1\%) são devido ao excesso de trabalho $(51,6 \%)$; ao sedentarismo $(32,8 \%)$ e ao isolamento social $(28,1 \%)$. O desconforto visual e a dor de cabeça é devido, principalmente, ao excesso de trabalho e a inadequação do espaço físico.

O excesso de trabalho, segundo Molino et al. (2020) acarreta um efeito chamado de tecnoestresse. Esse efeito faz com que os teletrabalhadores se sintam forçados a trabalhar mais rápido e por mais tempo (tecnosobrecarga), o que gera invasão de tecnologia em suas vidas privadas. Além disso, há a associação do tecnoestresse ao conflito trabalho-família e ao estresse, pois os usuários estão sempre conectados, de modo a causar a sensação de ser constantemente acessível e sintonizado com questões de trabalho. Outra questão fundamental é que o excesso de trabalho pode gerar consequências negativas no teletrabalho, como: 
sedentarismo, cansaço, aumento da carga mental, dificuldade de concentração, dores no corpo e exaustão emocional (Síndrome de Burnout) (GODOY, 2019; SUH; LEE, 2017; SONG; GAO, 2019; CHARALAMPOUS et al., 2019).

\begin{tabular}{|c|c|c|c|c|c|c|c|}
\hline & & & quênc & lo des & forto ( & & \\
\hline $\begin{array}{l}\text { Tab } \\
\text { resp }\end{array}$ & $\begin{array}{l}\text { lação de referência cruzada: desconforto e causas (63 } \\
\text { ondentes) }\end{array}$ & 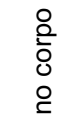 & 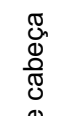 & 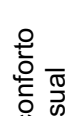 & 离 & 足 & 흄 \\
\hline & Sedentarismo - Não pratico atividade física & 32,8 & 10,9 & 15,6 & 29,7 & 7,8 & 37,5 \\
\hline & Excesso de trabalho & 51,6 & 23,4 & 39,1 & 59,4 & 12,5 & 67,2 \\
\hline & $\begin{array}{l}\text { Já possuo problemas físicos que se intensificaram com o } \\
\text { trabalho em home office }\end{array}$ & 9,4 & 1,6 & 4,7 & 7,8 & 0 & 10,9 \\
\hline $\mathscr{8}$ & Distração & 12,5 & 6,3 & 12,5 & 20,3 & 3,1 & 20,3 \\
\hline$\sum_{\pi}^{0}$ & Interferências familiares e tecnológicas & 25 & 10,9 & 10,3 & 35,9 & 10,9 & 35,9 \\
\hline & Excesso de reuniões e interrupções provenientes do trabalho & 23,4 & 9,4 & 20,3 & 32,8 & 3,1 & 32,8 \\
\hline & Isolamento social & 28,1 & 14,1 & 18,8 & 39,1 & 6,3 & 43.8 \\
\hline & Inadequação do espaço físico & 25 & 15,6 & 26,6 & 35,9 & 15,6 & 42,2 \\
\hline & Não sei identificar & 3,1 & 0 & 0 & 3,1 & 0 & 4,7 \\
\hline Tot & & 68,8 & 26,6 & 48,4 & 82,8 & 20,3 & 100 \\
\hline
\end{tabular}

Tabela 5. Tabela de referência cruzada do número percentual de indivíduos que relataram ter desconforto e a causa do desconforto

Fonte: Elaborado pelos autores (2021).

O isolamento social, segundo Vicente-Herrero et al. (2018) gera riscos psicossociais ao trabalho. Neste sentido, alguns docentes relataram que o isolamento social, proporcionado pelo teletrabalho e pela pandemia, trouxe consequências para a saúde física e mental. Também foi informado sobre a dificuldade de comunicação entre os colegas de trabalho e o sentimento de não pertencimento à instituição na qual trabalham. A inadequação do espaço físico é o que gera grande parte dos problemas de saúde física e mental (GONZÁLEZ; TORRANO; GARCÍA-GONZÁLEZ, 2020; WERTH; BABSKI-REEVES, 2012). Os docentes relataram problemas de má postura e dores no corpo durante o trabalho. Mesmo os profissionais que possuem um home office apropriado afirmaram que a fadiga de trabalhar em casa, o cansaço visual e mental devido ao excesso de trabalho se sobressai aos problemas na estação de trabalho.

Questionados sobre quais requisitos e atributos do ambiente, no qual o professor realiza as atividades, promovem o desconforto, $75 \%$ dos docentes responderam que: a posição do computador ou o tamanho do computador (50,8\%); o ruído (47,6\%); a cadeira (44,4\%); o brilho e os reflexos de superfície (30,2\%); a mesa $(28,6 \%)$; a iluminação inadequada $(23,8 \%)$ e a temperatura $(11,1 \%)$ provocam o desconforto. Para $33,3 \%$ outros elementos causam o desconforto, como: (i) a falta de organização (necessidade de ter uma estante para livros e gavetas para organizar os objetos de trabalho); (ii) o espaço destinado ao trabalho ser pequeno; (iii) a ausência de um espaço exclusivo para o trabalho (nestes casos, os usuários relataram que a cama e o sofá são desconfortáveis); (iv) o uso intensivo de telas; (v) a divisão do ambiente com outro membro da família; (vi) a falta de tranquilidade no ambiente de trabalho e (vii) a ênfase na falta de ergonomia do mobiliário, como cadeira e mesa de trabalho pequenas e desconfortáveis.

A Tabela 6 apresenta a referência cruzada entre o desconforto e os atributos do espaço de trabalho. Observase que o cansaço mental é devido a posição do computador e/ou tamanho do computador (42,6\%); a cadeira $(39,3 \%)$, por permanecerem muitas horas sentado na mesma posição, além de não ser ergonômica; e o brilho 
e reflexo de superfícies $(31,1 \%)$. As dores no corpo também são devido a posição do computador $(41 \%)$ e a cadeira $(31,1 \%)$. O desconforto visual, devido a posição do computador $(31,1 \%)$ e ao brilho $(26,2 \%)$ e as dores de cabeça, por conta da posição do computador (18\%) e do brilho e reflexos das superfícies $(14,8 \%)$.

\begin{tabular}{|c|c|c|c|c|c|c|c|}
\hline \multirow{2}{*}{\multicolumn{2}{|c|}{$\begin{array}{l}\text { Tabulação de referência cruzada: desconforto e atributos do } \\
\text { espaço de trabalho ( } 63 \text { respondentes) }\end{array}$}} & \multicolumn{5}{|c|}{ Frequência do desconforto (\%) } & \multirow{3}{*}{$\begin{array}{l}\bar{\pi} \\
\text { 今0 } \\
42,6\end{array}$} \\
\hline & & \multirow{2}{*}{ 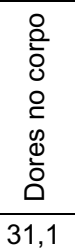 } & \multirow{2}{*}{ 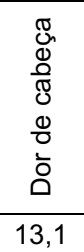 } & \multirow{2}{*}{ 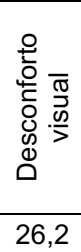 } & \multirow{2}{*}{ 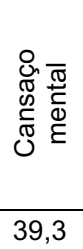 } & \multirow{2}{*}{ 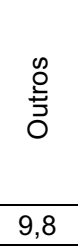 } & \\
\hline \multirow{8}{*}{ 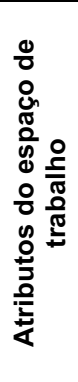 } & Cadeira & & & & & & \\
\hline & Mesa & 23 & 13,1 & 19,7 & 26,2 & 9,8 & 29,5 \\
\hline & Posição do computador/ tamanho do computador & 41 & 18 & 31,1 & 42,6 & 9,8 & 50,8 \\
\hline & lluminação inadequada & 18 & 9,8 & 16,4 & 23 & 4,9 & 23 \\
\hline & Brilho e reflexos de superfícies & 24,6 & 14,8 & 26,2 & 31,1 & 8,2 & 31,1 \\
\hline & Temperatura & 8,2 & 4,9 & 6,6 & 11,5 & 1,6 & 11,5 \\
\hline & Ruído & 31,1 & 11,5 & 23 & 37,7 & 9,8 & 45,9 \\
\hline & Outros & 26,2 & 9,8 & 11,5 & 24,6 & 13,1 & 34.4 \\
\hline \multicolumn{2}{|c|}{ Total } & 72,1 & 27,9 & 50,8 & 82 & 21,3 & 100 \\
\hline
\end{tabular}

Tabela 6. Tabela de referência cruzada do número percentual de indivíduos que relataram ter desconforto e os atributos do espaço de trabalho que mais causam o desconforto

Fonte: Elaborado pelos autores (2021).

Werth e Babski-Reeves (2012) afirmam que o uso de computadores compactos, laptop e tablets, usualmente apresentam um maior risco de lesão ou desenvolvimento de doenças nos membros superiores, especialmente pescoço. $\mathrm{O}$ aparecimento destes distúrbios musculoesqueléticos e a fadiga decorrente da utilização destes dispositivos são problemas de saúde física que influenciam as atitudes e o comportamento dos teletrabalhadores (GONZÁLEZ; TORRANO; GARCÍA-GONZÁLEZ, 2020). Janneck et al. (2017) complementam que a tela do dispositivo deve estar a uma distância mínima de $60 \mathrm{~cm}$ do campo de visão. No caso do brilho, Davis et al. (2020) sugerem que a estação de trabalho seja orientada para que os monitores fiquem posicionados perpendicularmente para a janela, de modo que as janelas fiquem atrás do monitor. Com relação a superfície da mesa, essa deve ser feita de material não reflexivo (JANNECK et al., 2017).

Com relação ao espaço de trabalho em casa, os professores apontaram suas emoções positivas e negativas (Figura 2). Para a representação gráfica das emoções, foi utilizado como base, o 'Circumplex of Affect' desenvolvido por Russell (1980). Os respondentes podiam selecionar mais de uma emoção, sendo assim, as emoções positivas assinalada por 76 respondentes $(90,5 \%)$ foram: prazer $(63,2 \%)$; motivação $(35,5 \%)$; felicidade (35,5\%); confiança (34,2\%); interesse (27,6\%); otimismo (32,9\%); orgulho (17,1\%); inspiração $(14,5 \%)$; serenidade $(14,5 \%)$ e valorização $(6,6 \%)$. As emoções negativas registrada por 77 docentes $(91,7 \%)$ foram: cansaço $(71,4 \%)$; ansiedade $(46,8 \%)$; tédio $(36,4 \%)$; solidão $(31,2 \%)$; medo $(23,4 \%)$; desapontamento (14,3\%); angústia (14,3\%); confusão (13\%); culpa (7,8\%) e apreensão $(5,2 \%)$. As emoções negativas possuem intensidade e recorrência maior do que as emoções positivas. Parte dos profissionais afirmaram que apesar do interesse e motivação pelo trabalho remoto, estes experenciaram cansaço e ansiedade em excesso. 


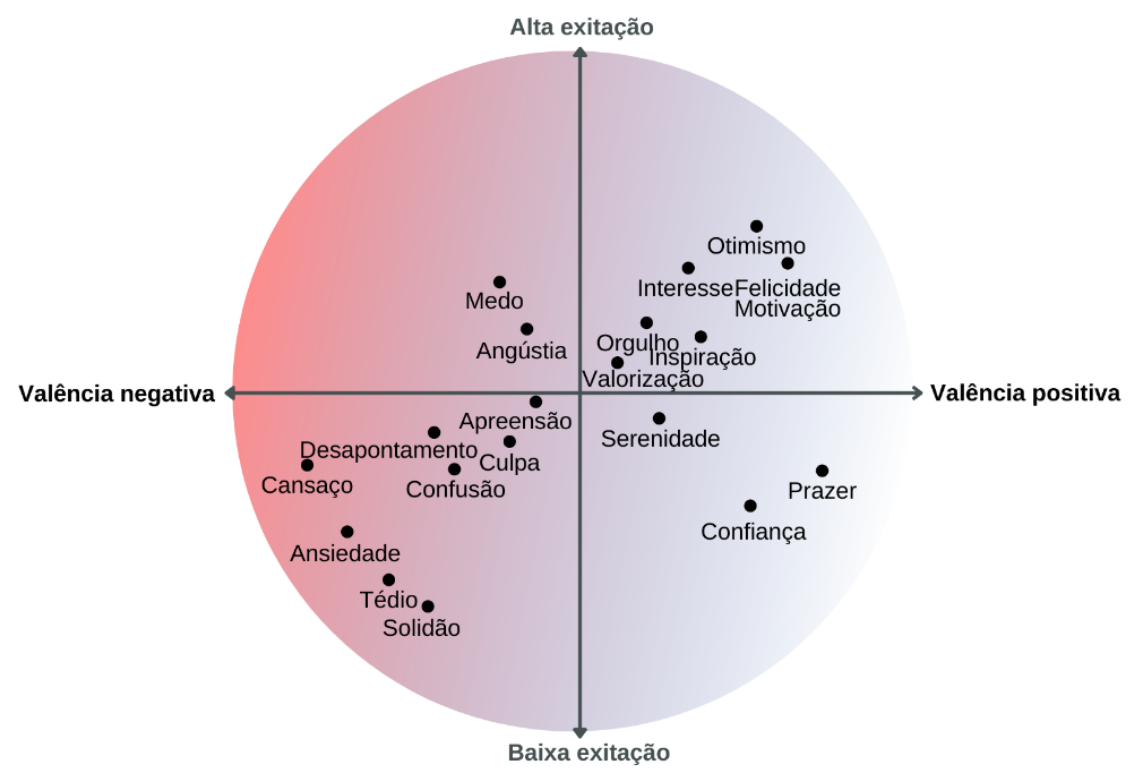

Figura 2. Representação gráfica das emoções positivas e negativas experienciadas pelos docentes Fonte: Elaborado pelos autores (2021).

Em seguida, os docentes indicaram o grau de satisfação com o ambiente de trabalho em casa (Figura 3), por meio de uma escala Likert de cinco pontos, sendo (1) muito insatisfeito; (2) insatisfeito; (3) neutro; (4) satisfeito e (5) muito satisfeito. Cerca de 35,7\% dos professores estão satisfeitos com o espaço de trabalho em casa e 33,3\% estão neutros. Para 20,2\% dos docentes, o grau é de muito satisfeito; $8,3 \%$ insatisfeito e $2,4 \%$ muito insatisfeito.

Para os que responderam de muito insatisfeito, insatisfeito e neutro, foi questionado como os professores gostariam que fosse o home office, e o que é mais importante para eles neste espaço. Assim, os docentes pontuaram que necessitam, no geral, de um local próprio para o trabalho e que este espaço seja isolado do restante da casa. Além disso, o espaço precisa ser prático e confortável. Também foi informada a necessidade de uma cadeira confortável e que permita suspender os pés; mesa maior; tela do computador maior e posicionada em uma altura adequada; iluminação natural e artificial apropriada; acústica (menos ruído, tanto do lado de fora da casa como do lado de dentro, sobretudo para os profissionais que gravam as aulas); internet de qualidade; estante para organizar materiais e papéis; teclado externo; suporte para colocar o laptop na altura dos olhos e conforto térmico (ventilação natural e ar condicionado).

Além disso, também foi perguntado como eles descrevem a experiência com relação ao trabalho realizado em casa e o espaço em que mais costumam trabalhar. A maioria dos docentes respondeu como sendo satisfatória, razoável e desafiadora. Grande parte dos professores se adaptaram para o modo remoto e perceberam vantagens com relação a flexibilidade de horários e um maior aproveitamento do tempo que gastavam com o deslocamento entre a casa e o trabalho (que passava de duas horas). Com isso, houve aumento da produtividade e concentração nas atividades. Entretanto, para os profissionais que possuem filhos ou familiares dependentes, a experiência tem sido desmotivadora e cansativa. Houve aumento nas tarefas domésticas e dificuldade de conciliação da casa com o trabalho, especialmente para os que possuem cônjuges que também estão trabalhando de forma remota.

Em termos de home office, os participantes acreditam que é necessário a aquisição de mobiliários e equipamentos ergonômicos, de modo a diminuir os desconfortos experenciados. Entretanto, foi mencionado o custo elevado no investimento de um mobiliário e equipamentos para a elaboração de aulas remotas de 
qualidade. Segundo os relatos, os docentes acreditam que a instituição deveria ter oferecido o mínimo de equipamentos para que o trabalho continuasse a ser desenvolvido.

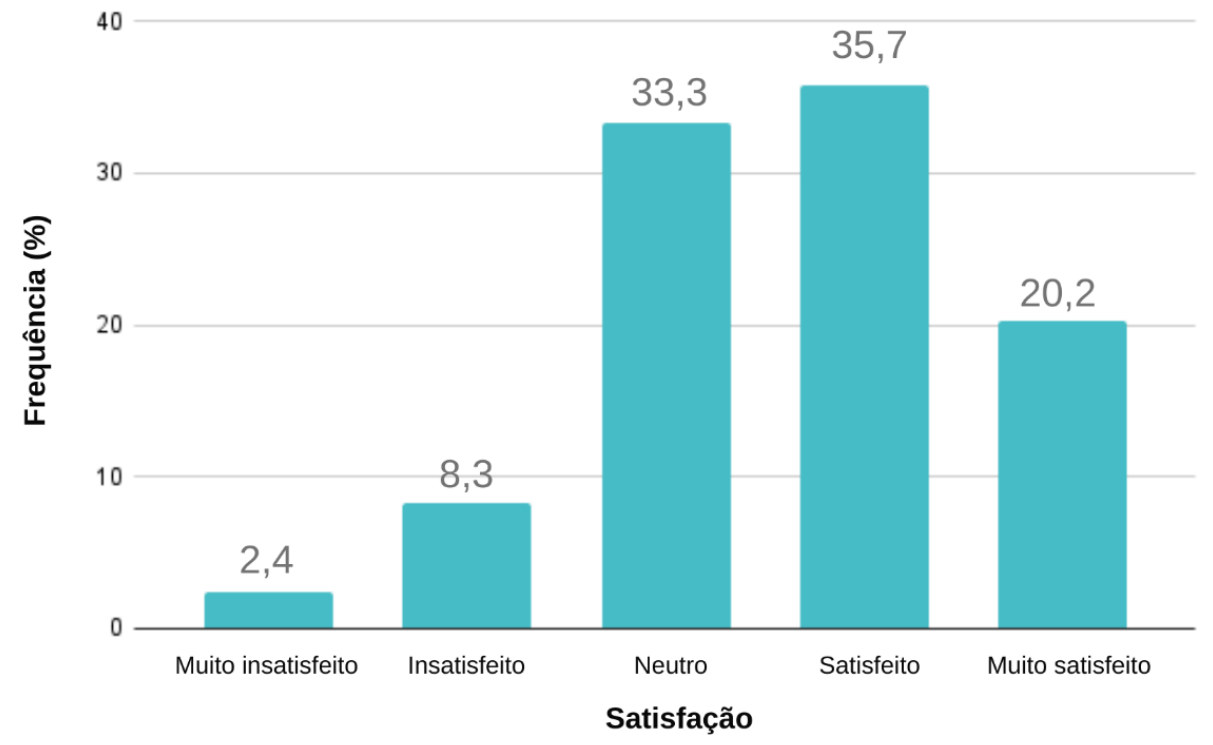

Figura 3. Grau de satisfação dos participantes com o trabalho remoto em home office Fonte: Elaborado pelos autores (2021).

Em contrapartida, alguns docentes mencionaram que o cansaço mental e as dores no corpo estão mais relacionados ao excesso de trabalho que um professor universitário enfrenta do que se o trabalho é realizado em casa ou na universidade. Como mencionado anteriormente, a carga de trabalho aumentou, gerando um maior estresse e cansaço, não só com o trabalho, mas devido ao pouco tempo que estes profissionais tiveram para se adaptarem. A tecnologia envolvida e as instabilidades com a internet também são as causas do estresse.

\section{Conclusão}

O estudo apresentou os resultados de uma pesquisa de inquirição sobre a experiência no trabalho remoto de professores do ensino superior de instituições públicas durante a pandemia. Foi constatado que o ensino remoto emergencial está associado ao aumento da carga de trabalho entre os acadêmicos, o que consequentemente, leva ao desconforto físico e mental, ao estresse, ao cansaço e à ansiedade.

Não foi observada evidência suficiente de que o espaço de trabalho em casa (home office) ou a falta de adaptação do ambiente para a realização do trabalho seja a causa do cansaço ou do desconforto. Pelo contrário, mais da metade dos profissionais estão satisfeitos com a estação de trabalho e gostariam de continuar suas atividades de forma híbrida, mesmo após o fim da pandemia. Para tanto, os profissionais sentem a necessidade de aprimorar o espaço de trabalho. Apesar de, em partes, ser uma consequência da situação atual, o excesso de trabalho foi apontado como a maior desvantagem da modalidade e a causa do desconforto. Neste sentido, há a necessidade de adequação à organização e a demanda do trabalho, enquanto durar a pandemia, e estudos futuros que se aprofundem na questão do trabalho remoto híbrido (aulas presenciais e trabalho remoto). $\mathrm{O}$ isolamento social e as interferências familiares e tecnológicas também são aspectos que influenciam no desconforto, entretanto, em um cenário sem pandemia, estes efeitos podem ser menores. Assim como foi apontado pelos participantes, os problemas identificados são devido ao fato de trabalharem e descansarem no mesmo ambiente e às restrições impostas pela pandemia. $\mathrm{O}$ teletrabalho 
apresenta vantagens e desvantagens, sendo assim, ao se adotar esta modalidade de trabalho é imprescindível que o profissional tenha as características desejadas e a organização forneça o suporte e treinamento necessário. No entanto, devido às medidas emergenciais, o teletrabalho não foi uma opção dos profissionais. Grande parte dos docentes utilizaram recursos próprios para a compra de equipamentos para o trabalho remoto e mobiliários ergonômicos. Os profissionais também não receberam treinamento em ergonomia para que o trabalho pudesse ser desenvolvido com conforto, somente suporte às ferramentas de ensino à distância. A vista disso, ao passo que a tecnologia e a conectividade promoveram a continuidade do trabalho, a autonomia e a flexibilização dos horários e das atividades, os docentes se sentiram impulsionados a trabalharem mais, impactando negativamente na saúde e na qualidade das relações de trabalho.

A relevância desta pesquisa está em contribuir com o conhecimento para a sociedade acadêmica, por meio de dados quantitativos e qualitativos, visando compreender a experiência do trabalho remoto de modo a aprimorá-la. Tendo em vista que a profissão em questão foi apontada como uma das mais desafiadoras e impactadas pela pandemia, para trabalhos futuros sugere-se ampliar a amostra e que esta seja representativa, além de incluir outras questões que envolvam o trabalho dos docentes que não foram abordadas neste estudo.

\section{Referências Bibliográficas}

BARRETT, L. F.; RUSSELL, J. A. The Structure of Current Affect: Controversies and Emerging Consensus. American Psychological Society, v. 08, n. 01, p. 10-14, 1999.

BENTLEY, T. A. et al. The role of organizational support in teleworker wellbeing: a sociotechnical systems approach. Applied Ergonomics, v. 52, p. 207-215, 2016. DOI: https://doi.org/10.1016/j.apergo.2015.07.019

BJÄRNTOFT, et al. Occupational and Individual Determinants of Work-life Balance among Office Workers with Flexible Work Arrangements. International Journal of Environmental Research and Public Health, v. 17, 2020. DOI: https://doi.org/10.3390/ijerph17041418

BORTOLAN, G. M. Z.; DOMENECH, S. C.; FERREIRA, M. G. G. Experiência do usuário de home office: uma análise da literatura. Human Factors in Design, v. 10, n. 19, p. 137-163, 2021a. DOI:

https://doi.org/10.5965/2316796310192021137

BRASIL. Decreto ${ }^{\circ} 9.057$ de 25 de maio de 2017. Regulamenta o art. 80 da Lei no 9.394, de 20 de dezembro de 1996, que estabelece as diretrizes e bases da educação nacional. Disponível em: http://www.planalto.gov.br/ccivil 03/ ato2015-2018/2017/decreto/d9057.htm. Acesso em: 01 jun 2021.

CHARALAMPOUS, M. et al. Systematically reviewing remote e-workers' well-being at work: a multidimensional approach. European Journal of Work and Organizational Psychology, 28, n. 1, p. 5173, 2019. DOI: https://doi.org/10.1080/1359432X.2018.1541886

DAVIS, K. G. et al. The Home Office: Ergonomic Lessons From the new normal. Ergonomics in Design, v. 28, n. 04, p. 04-10, 2020. DOI: https://doi.org/10.1177/1064804620937907

DIMA, A. M. et al. Sustainable Social and Individual Implications of Telework: A New Insight into the Romanian Labor Market. Sustentability, v.11, n. 13, 2019. DOI: https://doi.org/10.3390/su11133506

DWIDIENAWATI, D. et al. Is your Work from Home Job satisfying? Lesson Learned from Work from Homeduring COVID-19 Outbreak in Indonesia. Journal of the Social Sciences, v. 48, p. 743-752, 2020. 
FILARDI, F.; CASTRO, R. M. P.; ZANINI, M. T. F. Vantagens e desvantagens do teletrabalho na administração pública: análise das experiências do Serpro e da Receita Federal. Cadernos EBAPE-BR, 18, n. 01, p.28-46, 2018. DOI: https://doi.org/10.1590/1679-395174605

FONNER, K. L.; ROLOFF, M. E. Why Teleworkers are More Satisfied with Their Jobs than are OfficeBased Workers: When Less Contact is Beneficial. Journal of Applied Communication Research, v. 38, n. 04, p. 336-361, 2010. DOI: https://doi.org/10.1080/00909882.2010.513998

GARCÍA-SALIRROSAS, E. F.; SÁNCHEZ-POMA, R. A. Prevalencia de los trastornos musculoesquelético en docentes universitarios que realizan teletrabajo en tiempos de covid-19. Health Science, v. 81, n. 03, p. 301-307, 2020. DOI: http://dx.doi.org/10.15381/anales.v81i3.18841

GIL, A. C. Como elaborar projetos de pesquisa. 5. ed. São Paulo: Atlas, 2010.

GIMÉNEZ-NADAL, J. I.; MOLINA, J. A.; VELILLA, J. Work time and well-being for workers at home: evidence from the American Time Use Survey. International Journal of Manpower, 41, n. 02, p. 184-206, 2020. DOI: https://doi.org/10.1108/IJM-04-2018-0134

GODOI, M. et al. O ensino remoto durante a pandemia de covid-19: desafios, aprendizagens e expectativas dos professores universitários de educação física. Research, Society and Development, v. 9, n. 10, p. 1-19, 2020 .

GODOY, L. D. Satisfação no teletrabalho: construção de um instrumento de avaliação da satisfação de teletrabalhadores. Dissertação (Mestrado em Design), Programa de Pós-Graduação em Design, Universidade do Estado de Santa Catarina. Florianópolis, 2019. Disponível em:

https://www.udesc.br/arquivos/ceart/id_cpmenu/1229/Dissertacao_Ligia_Godoy_15718415587319_1229.pd f. Acesso em: 08 nov. 2021.

IPSEN, C. et al. Six Key Advantages and Disadvantages of Working from Home in Europe during COVID19. International Journal of Environmental Research and Public Health, v. 18, p. 1-18, 2021.

KIM, J. et al. Workplace Flexibility and Worker Well-Being by Gender. Journal of marriage and family, v. 82, n. 03, p. 892-910, 2020. DOI: https://doi.org/10.3390/ijerph18041826

KAZEKAMI, S. Mechanisms to improve labor productivity by performing telework. Telecommunications Policy, v. 44, n. 02, 2020. DOI: https://doi.org/10.1016/j.telpol.2019.101868

KIM, J. et al. Workplace Flexibility and Worker Well-Being by Gender. Journal of marriage and family, 82, n. 03, p. 892-910, 2020. DOI: https://doi.org/10.1111/jomf.12633

KOSSEK, E. E.; LAUTSCH, B. A.; EATON, S. C. Telecommuting, control, and boundary management: Correlates of policy use and practice, job control, and work-family effectiveness. Journal of Vocational Behavior, v. 68, p. 347-367, 2006. DOI: https://doi.org/10.1016/j.jvb.2005.07.002

LIMA, M. 78\% dos profissionais se sentem mais produtivos trabalhando remotamente. VOCÊ S/A, 2020. Disponivel em: https://vocesa.abril.com.br/carreira/78-dos-profissionais-se-sentem-mais-produtivostrabalhando-remotamente. Acesso em: 11 mar. 2021.

MACÊDO, T. A. M. et al. Ergonomics and telework: A systematic review. Work, 66, p. 777-788, 2020. DOI: http://doi.org/10.3233/WOR-203224 
MANCEBO, D. Trabalho remoto na Educação Superior brasileira: efeitos e possibilidades no contexto da pandemia. Revista USP, v. 127, p. 105-116, 2020. DOI: https://doi.org/10.11606/issn.2316-9036.i127p105$\underline{116}$

MANN, S.; HOLDSWORTH, L. The psychological impact of teleworking: stress, emotions and health. New Technology, Work and Employment, 18, n. 3, p. 196-211, 2003. DOI: https://doi.org/10.1111/1468005X.00121

MATTAR, F. N. Pesquisa de marketing: Metodologia, planejamento, execução e análise. Elsevier: 7.ed. 2014.

MOLINO, M. et al. Wellbeing Costs of Technology Use during Covid-19 Remote Working: An Investigation Using the Italian Translation of the Technostress Creators Scale. Sustentability, v. 12, n. 15, 2020. DOI: https://doi.org/10.3390/su12155911

MORAES, A. M.; MONT’ALVÃO, C. Ergonomia: Conceitos e Aplicações. Rio de Janeiro: 2AB, 2010.

MOROSINI, L. Sob a pressão das telas: docentes sofrem efeitos do isolamento social, sobrecarga do ensino remoto e mudanças na rotina. RADIS: Comunicação e Saúde, n. 217, p.27-30, out. 2020.

PASQUALI, L. Psicometria: teoria e aplicações. Brasília: Universidade de Brasília, 1998.

PLUTCHIK, R. The Emotion. Revised edition, Univerity Press of America, 1991.

RAMOS, D.; BUENO, J. L. O. A percepção de emoções em trechos de música ocidental erudita. Per Musi, Belo Horizonte, n.26, p.21-30, 2012. DOI: https://oi.org/10.1590/S1517-75992012000200003

RUSSELL, J. A. A circumplex model of affect. Journal of Personality and Social Psychology, v. 39, p. 1161-1178, 1980.

SONG, Y.; GAO, J. Does Telework Stress Employees Out? A Study on Working at Home and Subjective Well-Being for Wage/Salary Workers. Journal of Happiness Studies, 21, p. 2649-2668, 2020. DOI: https://doi.org/10.1007/s10902-019-00196-6

SUH, A.; LEE, J. Understanding teleworkers'technostress and its influence on job satisfaction. Internet Research, v. 27, n. 1, p. 140-159, 2017. DOI: https://doi.org/10.1108/IntR-06-2015-0181

VAN STEENBERGEN, E. F. et al. Transitioning Towards New Ways of Working: Do Job Demands, Job Resources, Burnout, and Engagement Change? Psychological Reports, 121, n. 04, p. 736-766, 2018. DOI: https://doi.org/10.1177/0033294117740134

VICENTE-HERRERO, M. T. et al. El teletrabajo en salud laboral: aspectos médico-legales y laborales. Revista CES Derecho, 9, n. 2, p. 287-297, 2018. DOI: http://dx.doi.org/10.21615/cesder.9.2.6

WANG, W.; ALBERT, L.; SUN, Q. Employee isolation and telecommuter organizational commitment. Telecommuters' Organizational commitment, v. 42, n. 03, p. 609.625, 2020. DOI: https://doi.org/10.1108/ER-06-2019-0246 


\section{Agradecimentos}

Os autores deste artigo agradecem ao CNPq, FAPESC e CAPES DS pela bolsa de estudos de doutorado (88887.488680/2020-00) e ao Programa de Pós-Graduação em Design da UDESC, pelo apoio na realização da pesquisa. 